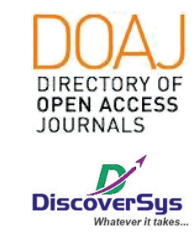

Published by DiscoverSys

\section{Eating habits and knowledge of nutrition status among medical students of Medical Faculty, Udayana University}

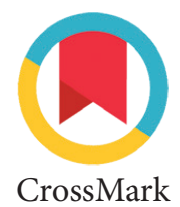

\author{
Dharsheinee K Vijayan, ${ }^{*}{ }^{*}$ Luh Seri Ani ${ }^{2}$
}

\section{ABSTRACT}

Introduction: Nutrition is the consumption of food, considered about the body's dietary essentials. Excellent nutrition is a sufficient, well-balanced diet joined with regular physical activity which is a foundation for satisfying health. On the other hand, poor nutrition can lead to low immunity, amplified susceptibility to diseases, impaired physical and mental development, and decreased productivity.

Method: This cross-sectional study was conducted on students of the medical faculty in University Udayana. There were 100 students were participated in this study, and they were divided into two groups. Of the total study participants, 50 were male, and 50 were female. They were asked to fill up a self-administered questionnaire. The variables that will be seen in this research is as follows; age, gender, weight, height, nutrition status, eating habit and knowledge.

Result: Majority of the respondents had fair to adequate knowledge of nutrition. However, the students have a poor eating habit.

Conclusion: Though the overall knowledge and nutrition status among the students were good, few minorities of the students held some misconceptions. On the other hand, the students have poor eating habits.

Keywords: eating habits, level of knowledge, nutrition status

Cite This Article: Vijayan, D.K., Ani, L.S. 2019. Eating habits and knowledge of nutrition status among medical students of Medical Faculty, Udayana University. Intisari Sains Medis 10(2): 244-248. D0I: 10.15562/ism.v10i2.406

${ }^{1}$ Medical Education Program ${ }^{2}$ Department of Community Medicine and Preventive Medicine Medical Faculty of Udayana University
"Correspondence to: Dharsheinee K Vijayan, Medical Education Program dharsh93@gmail.com

Received: 2019-02-02 Accepted: 2019-03-07 Published: 2019-08-01

\section{INTRODUCTION}

One fundamental factor that assists us to stay healthy and be energetic is good nutrition, which is created on healthy eating. Based on the World Health Organization (WHO), nutrition is the consumption of food, considered about the body's dietary essentials. Excellent nutrition is a sufficient, well-balanced diet joined with regular physical activity which is a foundation for satisfying health. On the other hand, poor nutrition can lead to low immunity, amplified susceptibility to diseases, impaired physical and mental development, and decreased productivity.

According to the data from the WHO, beyond 1.4billion grownups are overweight, and 2.8million grownups decease every year from chronic diseases that caused by overweight and obesity disorders. The Euromonitor International states that in AsiaPacific, obesity has remained greatly mounting and some countries are expected to have the maximum obesity level from the year 2010 to the year 2020 . The countries are Vietnam (225 percent obesity rate), Hong Kong (178 percent obesity rate), India (100 percent obesity rate), South Korea (80.7 percent obesity rate), New Zealand (52 percent obesity rate), and Indonesia (50 percent obesity rate). ${ }^{1}$
According to the National Eating Disorders Association (NEDA) summaries that the regular college freshman increases about 2.5 to 3.5 pounds in the initial year on campus, whereas between 25 percent to 32percent of university pupils will encounter an eating disorder. Adolescence is a period of speedy changes in the growth progression of physical, mental and psychosocial. During this phase, the event of sexual development and the reaching of adult form occurs because of the maturation of endocrine function. On the time of physical maturation progression, there will also be changes in body structure. During the period of a growth spurt, high nutrient requirements are needed as it relates to the size of the body. The express growth is normally accompanied by the growth of physical activity so that the nutritional requirements will rise as well. The research proved that one a man has reached the age of 20 years, then growth has stalled his body. It means that food is no longer functioning for body growth, but to maintain the nutritional status has been obtained or made better nutrition. Thus, the need for nutrient elements in adulthood has been rather constant, except in the case of abnormalities in the body, such 
as pain and so on. Thus, requiring him to get the nutritional needs than usual. ${ }^{2}$

A recent Cross-sectional population study using a dietary questionnaire previously constructed and tested was administered during university hours. Each section was evaluated separately. Regarding research methods, nutrition knowledge, attitudes and practices, socio-demographic factors, food frequency, weight, height, waist circumference (WC) and body mass index (BM) were evaluated. The results revealed that $42 \%$ of the students get their nutritional knowledge from the media. $73.4 \%$ Didn't know the source of vitamin B12 and iron. $55.1 \%$ of the students didn't know the food group that should be eaten the least. $52.6 \%$ didn't know which foods contain more fibers. $66.6 \%$ of students didn't know which foods contain the most calcium. The student field was significantly associated with several of these questions like food group that should be eaten the least and knowledge of foods containing calcium. Knowledge about carbohydrates, fat, and hazards of low intake of fruits and vegetables. Results from nutritional attitude reveal that only $46.3 \%$ of students attempt to eat healthily. $65.1 \%$ find it difficult to eat healthy in university cafeterias, $50.6 \%$ find it hard to have time to plan a healthy diet, while $50.6 \%$ enjoy eating unhealthy food. $30.9 \%$ of students never consume lentil, $28 \%$ never consume fish, $25.4 \%$ never consume lamp, and $25.4 \%$ never consume beef. BMI results showed that only $46.6 \%$ of students are of normal weight while $61 \%$ of students have an ideal WC. The study suggests the lack of adequate nutritional knowledge among students. ${ }^{3}$

\section{METHOD}

This study was a descriptive cross-sectional study to obtain data about the amount of knowledge about nutrition status among medical student at Udayana University, Denpasar, Bali. This study was conducted at Udayana University from November 2015 - January 2016. The sample in this study was taken from the students from batch 2013 and batch 2014 at Faculty of Medicine, Udayana University which fulfilled the inclusion criteria. The inclusion criteria are the participants were from both genders, stable mental status, and join the research willingly. 100 samples were taken using consecutive sampling technique. The samples were interviewed to obtain the data used to fill out the questionnaire. Descriptive analysis was used to process the data.

\section{RESULT}

The sample consisted of 100 students, $50 \%$ was female (25 from batch 2013 and 25 from batch 2014), and 50\% was male (25 from batch 2013 and 25 from batch 2014). The age range to answer this questionnaire was 18 years old and above. $100 \%$ of the participants are Asians.

Results showed that $2 \%$ were obese, $11 \%$ underweight, $20 \%$ overweight and $67 \%$ had normal healthy BMI status (Table 2) according to the WHO International classification of BMI. The prevalence of underweight was higher among the females (7\%) compared to the males (4\%), while more males were overweight (11\%) compared to the males (9\%). $2 \%$ of the male respondents were categorized as obese but non-from the female student was obese.

One hundred (100) medical undergraduate students comprising 50 males (50\%) and 50 females (50\%) participated in the study. The ages of the students ranged from 18 to 28 years. The result of food consumption and eating habits of the respondents showed that more than half of the students $(73 \%)$ ate three times daily while $12 \%$ ate twice a day (Table 3). Meal skipping was excessive among the selected university school students as $68 \%$ testified that they missed meals. Barely $32 \%$ do not skip meals. The main purpose for meal skipping was just habitual by the students (46\%). This observation could be attributed to the period in which the study was carried out. Moreover, $21 \%$ reported skipping a meal because of no time to eat, while $17 \%$ of the students which mostly consist of female students stated that the reason for meal skipping is to maintain their body. The highest meal skipped by the students was breakfast $(72 \%)$ followed by breakfast and lunch (14\%), and lunch and dinner (11\%), respectively. Snacking was also witnessed to be high among the students as 57\% of the students stated that they consumed snacks. The students gave reasons for snacking such as hunger (32\%), to make up for skipped meals (28\%), habit (26\%) and like (14\%), respectively. The major source of snacks for the students was outside of the university (51\%), while $41 \%$ obtained their snacks from the university premises, $8 \%$ from home.

Majority of the respondents had fair to adequate knowledge of nutrition. Eighty-three percent (83\%) defined nutrition as either the consumption of good food for the proper functioning of the body or related it to an expression of the importance of food to the body. Again, the majority of the respondents (78\%) indicated that people eat for growth and development. These responses were indicators that most respondents knew why food was eaten or had a 
Table 1 The Characteristic of Respondents

\begin{tabular}{lcc}
\hline Variables & Frequency & Percentage $\%$ \\
\hline Age & 0 & \\
$<18$ & 100 & $0 \%$ \\
$>18$ & & $100 \%$ \\
Gender & 50 & \\
Male & 50 & $50 \%$ \\
Female & & $50 \%$ \\
\hline
\end{tabular}

Table 2 Nutritional status of the respondents by gender

\begin{tabular}{lcccc}
\hline Sex & $\begin{array}{c}\text { Underweight } \\
\text { (\%) }\end{array}$ & $\begin{array}{c}\text { Healthy weight } \\
(\mathbf{\%})\end{array}$ & $\begin{array}{c}\text { Overweight } \\
(\mathbf{\%})\end{array}$ & Obese (\%) \\
\hline Male & $4(4 \%)$ & $33(33 \%)$ & $11(11 \%)$ & $2(2 \%)$ \\
Female & $7(7 \%)$ & $34(34 \%)$ & $9(9 \%)$ & $0(0 \%)$ \\
\hline
\end{tabular}

Table 3 Eating Habits of Respondents

\begin{tabular}{|c|c|c|}
\hline Variables & Frequency & Percentage \% \\
\hline \multicolumn{3}{|l|}{ The frequency of eating per day } \\
\hline Once & 5 & $5 \%$ \\
\hline Twice & 12 & $12 \%$ \\
\hline Thrice & 73 & $73 \%$ \\
\hline More than 3 times & 10 & $10 \%$ \\
\hline \multicolumn{3}{|l|}{ Meal Skipping } \\
\hline Yes & 68 & $68 \%$ \\
\hline No & 32 & $32 \%$ \\
\hline \multicolumn{3}{|l|}{ Reason for meal skipping } \\
\hline I don't like the food & 7 & $7 \%$ \\
\hline Fasting for religious reason & 9 & $9 \%$ \\
\hline No time to eat & 21 & $21 \%$ \\
\hline Just a habit & 46 & $46 \%$ \\
\hline To maintain my figure & 17 & $17 \%$ \\
\hline \multicolumn{3}{|l|}{ Meal skipped } \\
\hline Breakfast & 72 & $72 \%$ \\
\hline Lunch & 3 & $3 \%$ \\
\hline Breakfast and Lunch & 14 & $14 \%$ \\
\hline Lunch and Dinner & 11 & $11 \%$ \\
\hline \multicolumn{3}{|l|}{ Snacking } \\
\hline Yes & 57 & $57 \%$ \\
\hline No & 43 & $43 \%$ \\
\hline \multicolumn{3}{|l|}{ Reason for snacking } \\
\hline I like them & 14 & $14 \%$ \\
\hline Hunger & 32 & $32 \%$ \\
\hline Habit & 26 & $26 \%$ \\
\hline To make up for skipped meal & 28 & $28 \%$ \\
\hline \multicolumn{3}{|l|}{ Source of snack } \\
\hline University premises & 41 & $41 \%$ \\
\hline Home & 8 & $8 \%$ \\
\hline Outside University premises & 51 & $51 \%$ \\
\hline
\end{tabular}

fair knowledge about the primary functions of food in humans. The general description of a balanced diet by the respondents was also fairly good, with $80 \%$ giving a good description of a balanced diet (Table 4). The discoveries also disclosed that nearly all the respondents had a fairly good knowledge of food sources that provide nutrients to perform the three major functions in the body.

\section{DISCUSSION}

The result of this study showed the prevalence of obesity $(7 \%)$ is smaller than the prevalence of overweight (18\%). In the year 2003-2004, 17.1\% of USA adolescents were overweight, and $32.2 \%$ of adults were obese. There are significant results shows that the prevalence of overweight and obesity increases from $14.0 \%$ to $18.2 \%$ from the year 2003-2004. ${ }^{4}$

Based on the research done in Universitas Udayana, we can conclude that the students have a poor eating habit. A high number of $68 \%$ of students skips their daily meal with $46 \%$ giving the reason as it has become their habit. It is known that breakfast is the most important meal of the day. However, $72 \%$ of the students skip their breakfast. Based on another study, we found that about $15.7 \%$ of students ate meals regularly, while $48 \%$ rarely did so. More than $58 \%$ of the students stated that they consume fast foods. These were in agreement with some researchers who explained that skipping breakfast was significantly greater in females $62.8 \%$ compared to males $37.2 \% .^{5}$ This study revealed that $68.8 \%$ of the students skipped meals and the breakfast was the meal mostly skipped (40.4\%). The skipping of breakfast has been associated with lower nutritional status and the risk of cardiovascular diseases. It has also been reported that less adequate breakfast habits may contribute to the appearance and further development of obesity. Therefore, the importance of regular eating patterns cannot be overemphasized in nutritional education. ${ }^{6}$

The medical students of Universitas Udayana Bali have a fair to adequate among of knowledge towards nutrition. The high level of knowledge could be attributed to access to nutrition education from counseling sessions at the hospital, workshops organized by NGOs or the associations which they belong. It is also important to note that almost all the respondents had some form of education from basic to tertiary levels, indicating that they may have been taught basic nutrition at the formal setting as well. It is encouraging to note that the hospital, associations, and workshops being organized for the respondents were providing some nutrition education to them. ${ }^{7}$ 
Table 4 Nutrition Knowledge of Respondents

\begin{tabular}{|c|c|c|}
\hline Variables & Frequency & Percentage \% \\
\hline \multicolumn{3}{|l|}{ Definition of Nutrition } \\
\hline Eating good food for good health & 44 & $44 \%$ \\
\hline Related to the importance of food to the body & 39 & $39 \%$ \\
\hline No idea & 17 & $17 \%$ \\
\hline \multicolumn{3}{|l|}{ Reasons for eating } \\
\hline To satisfy hunger & 16 & $16 \%$ \\
\hline For Growth and Development & 78 & $78 \%$ \\
\hline All of the above & 6 & $6 \%$ \\
\hline \multicolumn{3}{|l|}{ Description of a balanced diet } \\
\hline A diet containing all the necessary nutrients & 46 & $46 \%$ \\
\hline Diet with the appropriate amount of each nutrient & 34 & $34 \%$ \\
\hline No idea & 20 & $20 \%$ \\
\hline \multicolumn{3}{|l|}{ Energy giving foods? } \\
\hline Starchy Staples & 91 & $91 \%$ \\
\hline Fats and oils & 9 & $9 \%$ \\
\hline \multicolumn{3}{|l|}{ Body-Building foods? } \\
\hline Animal foods and products & 95 & 95 \\
\hline Legumes and nuts & 5 & 5 \\
\hline \multicolumn{3}{|l|}{ Protective foods? } \\
\hline Fruits and vegetables & 100 & 100 \\
\hline Animal foods and products & 0 & 0 \\
\hline
\end{tabular}

A negative correlation, although not statistically significant, existed between nutrition knowledge and diet quality of the respondents an indication that in this study sample nutrition knowledge is independent of the quality of diet. This finding is consistent with the work conducted by Zifferblaft and Wilbur who observed in their study in Mexico that nutrition knowledge and dietary practices were not strongly correlated. Therefore, nutrition knowledge per se does not seem to lead to direct action when individuals are unable to apply the knowledge for several reasons. Again, there was a positive correlation between nutrition knowledge and nutritional status although it was not statistically significant, suggesting that the nutrition knowledge of respondents did not affect their nutritional status. It is believed that education entails changing peoples' paradigms in the way they eat. It entails teaching to use the foods that are available to them locally, and to use them in a balanced way. The respondents through nutrition counseling and education might have been encouraged to eat new foods available locally in nutritionally balanced combinations. It is usually done to help them increase their food intakes so they can meet their energy and nutrient needs. $^{8}$

\section{CONCLUSION}

Our findings reveal that the majority of students were classified into the healthy BMI group. Nutrition knowledge is needed for better dietary choices. It is, therefore, recommended that a nutrition education program is developed and implemented for this group of adolescents, as nutrition education can be an accessible and effective tool for improving food choices. The meal and snack patterns in medical students of University Udayana were very poor. Our findings suggest the need for strategies designed to improve competence in the area of nutrition, especially concerning information relating to sources of nutrition and healthy weight management. Furthermore, public demand for health and nutritional information should be taken into consideration when implementing strategies aimed at improving the nutritional well-being of individuals

\section{REFERENCES}

1. CDC. Division of Nutrition, Physical Activity, Overweight and Obesity, DNPAO. CDC. 2016. Available: https://www. cdc.gov/nccdphp/dnpao/index.html. Accessed: $13^{\text {th }}$ Jan 2016. 
2. National Eating Disorders Association. Get the Facts on Eating Disorders, National Eating Disorders Association. 2016. Available: https://www.nationaleatingdisorders.org/ blog/get-facts-eating-disorders-infographics. Accessed: $5^{\text {th }}$ Jan 2016.

3. Elhassan MR., Gamal HE., \& Mohammed GS. Nutrition knowledge attitude and practices among students of Ahfad University for women. Indian Journal of Scientific Researc. h2013. 4(1), 25.

4. Ogden CL., Carroll MD., Curtin LR., McDowell MA., Tabak CJ., \& Flegal KM. Prevalence of overweight and obesity in the United States, 1999-2004. Jama. 2006. 295(13), 1549-1555.

5. Musaiger A., Bader Z., Al-Roomi K., \& D'Souza R. Dietary and lifestyle habits amongst adolescents in Bahrain. Food \& nutrition research. 2011. 55(1), 7122.

6. Essien E., Emebu PK., Iseh KR., \& Haruna MJ. Assessment of nutritional status and knowledge of students from selected secondary schools in Sokoto metropolis, Sokoto State, Nigeria. African Journal of Food, Agriculture, Nutrition and Development. 2014. 14(6), 2254-2268.
7. Cluskey, Mary, and Deana G. College Weight Gain and Behavior Transitions: Male and Female Differences. Journal of the American Dietetic Association. 2009. 109(2): 325-329. Web.

8. Zifferblaft S., Wilbur CS., 'Dietary Counseling: Some Realistic Expectations and Guidelines', Elsevier, Journal of American Dietetic Association. 1977. 70(6), 591-599

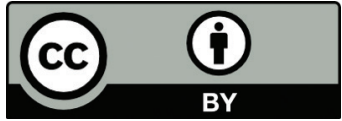

This work is licensed under a Creative Commons Attribution 